\title{
Education and employment status of adults with autism spectrum disorders in Germany - a cross-sectional-survey
}

\author{
Fabian Frank ${ }^{1,2^{*}}$ D , Martina Jablotschkin ${ }^{1,3}$, Tobias Arthen ${ }^{1}$, Andreas Riedel ${ }^{1}$, Thomas Fangmeier ${ }^{1}$, Lars P. Hölzel ${ }^{1,4}$ \\ and Ludger Tebartz van Elst ${ }^{1}$
}

\begin{abstract}
Background: Adults with autism spectrum disorders (ASD) experience challenges in participating in the labour market and struggle to achieve and maintain appropriate professional positions, possibly due to impairments of communication and social interaction. Studies have shown high rates of unemployment as well as evidence of inadequate employment. As knowledge on the participation in the German labour market is scarce, the aim of our study was to examine employment status, type of occupation and inadequate employment in a sample of clinically mostly late-diagnosed and most likely not intellectually disabled adults with ASD in Germany.

Methods: We conducted a cross-sectional-survey in clinically mostly late-diagnosed adults with ASD. Employment status, type of occupation, and the level of formal education and training were examined through a postal questionnaire. Inadequate employment regarding participants' current and longest practised occupation was assessed by transforming participants' information into skill levels of the "Classification of Occupations 2010" of the German Federal Employment Agency, and comparing these with participants' level of formal education and training.

Results: The response rate was $43.2 \%$ ( $N=185$ of $N=428$ potential participants). 94.6\% were first-time diagnosed when being 18 years of age or older. $56.8 \%$ held a general university entrance-level qualification and $24.9 \%$ had obtained a Masters' or diploma degree as their highest vocational qualification. 94.1\% had been employed at some time. Of these, $68.4 \%$ reported being currently employed, $13.5 \%$ being currently unemployed and $17.0 \%$ being retired for health reasons. Regarding the longest-practised and the current occupation, the highest proportion of participants was found in the occupational area "health and social sector, teaching and education" (22.4\% and 23.3\%, respectively). With respect to inadequate employment, $22.1 \%$ were found to be overeducated in relation to their longest-practised occupation and $31.3 \%$ in relation to their current occupation. This is significantly higher than the percentage of overeducation in the general population.
\end{abstract}

Conclusions: Despite largely high formal qualifications, the clinically mostly late-diagnosed adults with ASD represented in our sample are disadvantaged regarding their participation in the German labour market, especially with respect to rates of unemployment, early retirement and overeducation. Employment support programs should be developed to improve employment outcomes.

Keywords: Autism, Asperger syndrome, High functioning, Employment, Education, Adults

\footnotetext{
* Correspondence: fabian.frank@uniklinik-freiburg.de

${ }^{1}$ Department of Psychiatry and Psychotherapy, Medical Center - University of

Freiburg, Faculty of Medicine, University of Freiburg, Hauptstraße 5, 79104

Freiburg, Germany

${ }^{2}$ Department of Social Work, Protestant University of Applied Sciences

Freiburg, Bugginger Straße 38, 79114 Freiburg, Germany

Full list of author information is available at the end of the article
}

(c) The Author(s). 2018 Open Access This article is distributed under the terms of the Creative Commons Attribution 4.0 International License (http://creativecommons.org/licenses/by/4.0/), which permits unrestricted use, distribution, and reproduction in any medium, provided you give appropriate credit to the original author(s) and the source, provide a link to the Creative Commons license, and indicate if changes were made. The Creative Commons Public Domain Dedication waiver (http://creativecommons.org/publicdomain/zero/1.0/) applies to the data made available in this article, unless otherwise stated. 


\section{Background}

Autism spectrum disorders (ASD) are associated with qualitative impairment in using and contextualizing communication for social purposes and the capacity to process socially relevant information, and with restrictive repetitive behaviour patterns $[1,2]$. Given that the capacity to process socially relevant information and to interact in a socially suitable manner are essential requirements in occupational environments, everyday work processes can pose major challenges for adults with ASD [3], as most workplaces require adherence to social norms and decorum. With respect to social and sensory issues interfering with their job performance [4] as well as potential problems regarding their ability to manage social and interactional aspects of work $[5,6]$, earlier studies revealed challenges in obtaining, securing and maintaining employment in adults with ASD [7-9]. Furthermore, successful participation in the labour market can be hindered by differences with employers, for example regarding the understanding of productivity requirements or required support in work [10], and by possible ASD-related problems, for example prioritization and self-organization of work-tasks.

Even in adults with ASD and no co-occuring intellectual disability, studies show high rates of unemployment up to $60 \%[4,5,8,9,11-14]$. In this context, it is important to recognize that adults with ASD are often high educational achievers in terms of school and university qualifications $[12,13]$ and therefore apparently have good prerequisites for adequate participation in the labour market. However, a recent Australian study by Baldwin et al. [15] showed that $46.2 \%$ of employed adults with ASD were inadequately employed or overeducated, meaning that their highest level of formal education and training exceeded the occupational skill level needed for their current occupation. These findings indicate that even though individuals with ASD often possess high levels of formal education and training $[12,15]$ and desire to work [16], adults with ASD often struggle to participate in the labour market or to achieve and maintain appropriate professional positions.

Apart from studies reporting rates of $60 \%$ not-working (employable age, but no occupation due to i.e. being retired for health reasons, being homemaker or being unemployed) [12] or of $36.0 \%$ being unemployed [4] knowledge on the participation of adults with ASD in the German labour market in terms of adequate employment is scarce. Therefore, the aim of our study was to examine, by means of a cross-sectional-survey, the integration of a sample of clinically mostly late-diagnosed and most likely not intellectually disabled adults with ASD in the German labour market in terms of employment status, type of occupation and, in particular, regarding adequate or inadequate employment in terms of over- or undereducation.

\section{Methods}

\section{Design and sample}

The study population of the present postal crosssectional-survey consists of a sample of clinically mostly late-diagnosed and most likely not intellectually disabled individuals with ASD who attended the "specialised outpatient assessment clinic for ASD in adulthood" (Spezialsprechstunde für Autismus-Spektrum-Störungen im Erwachsenenalter) of the Medical Center - University of Freiburg for diagnostic analysis between September 2009 and March 2014. Clinically late-diagnosed means, that ASD was first time diagnosed when individuals were in adult age of 18 years or older. Diagnostic analysis was based on a structured clinical examination following ICD-10 and DSM-IV criteria, the NICE-Guidelines [17] and the German S3-Guidelines for diagnosing ASD [18]. A detailed description of the diagnostic approach and of the procedures and measures used is provided elsewhere $[12,19]$. All individuals aged 18 years or older diagnosed with ASD during this consultation between September 2009 and March 2014, who did not object to being contacted for research purposes, were included in the study. Formal IQ-testing was not part of the diagnostic process in all of these individuals. Of those individuals who have undergone formal IQ-testing, no individual possessed an IQ-score below 70. Furthermore, based on the educational performance and other assessments, we do not except any of the diagnosed individuals to be ranged as intellectually disabled. Therefore, it is most likely, that there are no individuals with co-occuring intellectual disability represented in our initial sample. Between September 2009 and March 2014, $N=485$ individuals were diagnosed with ASD. $N=57$ objected being contacted for research purposes. Therefore, the potential study population comprised $N=428$ adults with ASD. In October 2015 these individuals received information on the study and a questionnaire by post. A post-paid and postaddressed return envelope was enclosed, and a reminder letter was sent to all potential participants after two weeks, as these measures are associated with an increased response rate [20]. The survey was conducted with full anonymity and participation was voluntary. The study was approved by the Ethics Review Committee of the Medical Centre - University of Freiburg (number: 288/15).

\section{Measures and procedures}

Regarding the level of formal education and training, the employment status, the type of occupation, and the occupational skill level, the following measures were obtained or derived from participants.

\section{Employment status}

Initially, participants were asked whether they had ever been employed (yes/no). Thereupon, participants who 
had ever been employed were asked whether they were employed at present (yes/no) and, if so, how many hours they usually worked per week and whether their employment was located in a sheltered environment (yes/no). Additionally, participants who had ever been employed were asked whether they rated themselves as currently unemployed (yes/no), for how many months they had been unemployed within the last five years, and whether they had already retired (yes/no), and for which reasons (age, early retirement, health reasons).

\section{Type of occupation}

To classify the occupation type for the current and the longest practised occupation, the survey asked participants to record (a) their professional activity, (b) their subject area, and (c) their economic sector within short open-ended questions for both, the current and the longest practised occupation. This information was used to assign each participant to an occupational grouping according to the "Classification of Occupations 2010" (Klassifikation der Berufe 2010; KldB) of the German Federal Employment Agency [21]. The KldB codes all jobs and occupations in the German labour market by means of a five-digit documentation code. The first digit describes the occupational area, the second indicates the major occupational group, the third represents the sub-major occupational group, the fourth shows the minor occupational group, and the fifth describes the occupational skill level [21]. To ensure a consistent transformation of participants' occupational information into the KldB classification, an online database of the German Federal Employment Agency was used [22]. The occupational information recorded by the participants was entered into this database and automatically transformed into the five-digit documentation code of the $\mathrm{KldB}$. Additionally the derived KldB five-digit documentation codes of every participant were manually reviewed for plausibility and adjusted if necessary. An explanatory example for the transformation of participants' information into KldB five-digit documentation codes - in this case the documentation code for a medical specialist in psychiatry - is given in Table 1.
To assess differences from the general population, participants' data regarding the occupational area (first digit of the KldB five-digit documentation codes) of the current occupation was compared to data from the German Federal Employment Agency [23].

\section{Occupational skill level and level of formal education}

The fifth digit of each occupation listed within the KldB describes the occupational skill level. The KldB comprises four skill levels, which are differentiated as follows: level 1 - assistant or semi-skilled occupational activities; level 2 - professional oriented occupational activities; level 3 - complex specialist occupational activities; level 4 - highly complex occupational activities [23]. According to the Institute for Employment Research (Institut für Arbeitsmarkt- und Berufsforschung) of the German Federal Employment Agency skill levels are primarily defined by the required level of formal education and training [24], as shown in Table 2.

For each participant, the occupational skill level was recorded based on the previously derived KldB five-digit documentation code. To assess inadequate employment, i.e. over- or undereducation in relation to the current and the longest-practised occupation, we compared the skill level of the related KldB documentation code with the skill level derived from the level of formal education and training. Inadequate employment in terms of overeducation is assumed if a lower KldB skill level is accompanied by a higher KldB level of formal education and training. Conversely, undereducation is indicated if a higher KldB skill level is accompanied by a lower KldB level of formal education and training. Overeducation and undereducation were examined for both the longest-practiced occupation and the occupation pursued at the time of the survey. To assess differences compared to the general population, participants' data regarding over- or undereducation with respect to the current occupation was compared to data derived from the employment statistics of the German Federal Employment Agency [25].

Table 1 Example for transformation of participants' information into KldB codes

\begin{tabular}{|c|c|c|c|c|c|}
\hline \multicolumn{6}{|c|}{ Description of occupation within the survey } \\
\hline survey Item & professional activity & \multicolumn{2}{|l|}{ subject area } & \multicolumn{2}{|l|}{ economic sector } \\
\hline example & physician & \multicolumn{2}{|l|}{ psychiatry } & \multicolumn{2}{|l|}{ health care system } \\
\hline \multicolumn{6}{|c|}{ Transformation in 5-digit documentation code of the $\operatorname{KldB}[21,22]$} \\
\hline \multirow[t]{2}{*}{ structure } & \multirow[t]{2}{*}{ occupational area } & \multicolumn{3}{|c|}{ occupational group } & occupational skill level \\
\hline & & major & sub-major & minor & \\
\hline 5-digit code & 8 & 1 & 4 & 6 & 4 \\
\hline explanation & health and social sector & medical health & human and dental medicine & psychiatric consultant & $\begin{array}{l}\text { highly complex occupational } \\
\text { activities }\end{array}$ \\
\hline
\end{tabular}


Table 2 Formal level of education and training transferred to $\mathrm{KldB}$

\begin{tabular}{lcc}
\hline Formal level of education & KldB occupational skill level \\
\hline $\begin{array}{l}\text { Master's degree or Diploma university } \\
\text { Master's degree or Diploma university } \\
\text { of applied sciences }\end{array}$ & 4 & $\begin{array}{l}\text { highly complex } \\
\text { occupational activities }\end{array}$ \\
$\begin{array}{l}\text { Bachelor's degree: university or university } \\
\text { of applied sciences/technical college }\end{array}$ & 3 & $\begin{array}{l}\text { complex specialist } \\
\text { occupational activities }\end{array}$ \\
$\begin{array}{l}\text { Apprenticeship II: technical school, } \\
\text { master school or vocational academy }\end{array}$ & & \\
$\begin{array}{l}\text { Apprenticeship I: dual system of } \\
\text { vocational and educational training } \\
\text { within vocational schools and/or } \\
\text { companies }\end{array}$ & 2 & $\begin{array}{l}\text { professional orientated } \\
\text { occupational activities }\end{array}$ \\
Other vocational qualification & & \\
No vocational qualification & 1 & $\begin{array}{l}\text { assistant or semi-skilled } \\
\text { occupational activities }\end{array}$ \\
\hline
\end{tabular}

\section{Sociodemographic and clinical variables}

Sociodemographic data (age, sex, marital and relationship status, school-leaving qualification) and presence of comorbidities were collected using the German Health Interview and Examination Survey for Adults [26]. Additional clinical variables (ASD diagnosis, age at first-time ASD diagnosis) were collected using self-constructed items.

\section{Pretest}

Since individuals with ASD often have peculiarities in their understanding and use of language [27], impairment of linguistic pragmatics was considered in the construction of the questionnaire. Therefore, the endeavor was to use comprehensible and unequivocal formulation, which was examined within a pretest in five adults diagnosed with ASD using think-aloud methodology [28]. The questionnaire was then adapted linguistically and visually based on the results of this pretest. The final version of the questionnaire is available in German as a supplementary file (see Additional file 1).

\section{Statistical analysis}

Descriptive data analysis was performed using IBM SPSS Statistics for Windows, version 21. Comparisons of participants' data with data from the general population were conducted using Chi-square tests.

\section{Results}

The response rate was $43.2 \%(N=185$ of $N=428$ potential participants). Participants' sociodemographic and clinical characteristics are summarized in Table 3.

The majority of the participants is male (61.6\%) and the mean age of the sample was 39.5 (SD 11.3) years (c.f. Table 3). $36.6 \%$ were in a long-term relationship. The most frequent self-reported ASD diagnosis was asperger's syndrome (78.9\%), while the mean age at first-time diagnosis of any ASD was 34.7 (SD 12.5) years. 94.6\% were 18 years of age or older at first-time diagnosis of any ASD and hereby can be classified as clinically latediagnosed. The most frequent self-reported comorbidity was depression, at $48.9 \%$ (c.f. Table 3 ).

\section{Level of formal education and training}

Regarding the general education level, $11.9 \%$ of the participants held a certificate of basic secondary education (German: Hauptschulabschluss; 9 years school attendance; lower secondary level), 28.6\% had a general certificate of secondary education (German: Realschulabschluss; 10 years school attendance; lower secondary level), 56.8\% had a general university entrance-level qualification (German: Hochschulreife; 12 or 13 years school attendance; upper secondary level), and $2.7 \%$ had no school-leaving certificate or had a qualification that was not further specified (missing data $N=0$ ).

With regard to the level of formal education and training according to the $\mathrm{KldB}, 13.3 \%$ of the participants were assigned to skill level 1 (10.5\% no vocational qualification; $2.8 \%$ other vocational qualification), $43.1 \%$ to skill level 2 (43.1\% apprenticeship I), $12.7 \%$ to skill level 3 (8.8\% apprenticeship II; 3.9\% Bachelor's degree), 24.9\% to skill level 4 (8.8\% Master's or diploma degree from university of applied sciences; $16.0 \%$ Master's or diploma degree from university), and $6.1 \%$ were still in vocational education and training, meaning that their skill level was not specified within the KldB classification (missing data $N=4$ ).

\section{Employment status}

Regarding the employment status, 94.1\% $(N=174)$ of the participants reported having ever been employed (missing data $N=0)$. Of these, 68.4\% $(N=119)$ reported being employed at present, with an average number of $33.3 \mathrm{~h}$ worked per week (SD 12.1; missing data $N=6$ ) and $8.0 \%$ reported working in a sheltered workshop (missing data $\mathrm{N}=6$ ). Regarding the current employment situation of participants who had ever been employed, $17.0 \%$ were in early retirement for health reasons (missing data $N=3$ ) and $13.5 \%$ stated that they were unemployed (missing data $\mathrm{N}=3$ ). Of those who had ever been employed, $49.0 \%$ reported no periods of unemployment in the five years prior to this survey (missing data $\mathrm{N}=17$ ). Participants with periods of unemployment within this time frame $(N=80)$ reported an average of 24.4 (SD 20.0; Range 0.50 to 60.00) months of unemployment in the last five years (missing data $\mathrm{N}=0$ ).

\section{Type of occupation}

Apart from the occupational area "armed forces", all KldB occupational areas were represented in the study sample (c.f. Table 4). 
Table 3 Sociodemographic and clinical characteristics

\begin{tabular}{|c|c|c|c|}
\hline \multicolumn{4}{|l|}{ Sociodemographic Characteristics } \\
\hline Gender $(N=185)$ & & Family status $(N=183)^{d}$ & \\
\hline male $^{a}$ & 61.6 & unmarried $^{a}$ & 71.0 \\
\hline Age $(N=185)$ & & married $^{\mathrm{a}}$ & 22.4 \\
\hline mean $(S D)^{b}$ & $39.5(11.3)$ & divorced $^{\mathrm{a}}$ & 6.6 \\
\hline minimum ${ }^{c}$ & 21 & Relationship status $(N=183)^{\mathrm{d}}$ & \\
\hline maximum $^{c}$ & 64 & long-term relationship $>6$ months ${ }^{a}$ & 36.6 \\
\hline \multicolumn{4}{|l|}{ Clinical Characteristics } \\
\hline Primary Diagnosis $(N=185)$ & & Comorbidities $^{a, e, f}(N=184)$ & 70.1 \\
\hline asperger $^{a}$ & 78.9 & Depression $^{a}$ & 48.9 \\
\hline atypical $^{a}$ & 9.7 & orthopedic diseases $^{a}$ & 19.0 \\
\hline infantile ${ }^{a}$ & 4.3 & $O C D^{a}$ & 13.0 \\
\hline not specified / unknown ${ }^{a}$ & 7.1 & respiratory diseases ${ }^{a}$ & 11.4 \\
\hline Age when diagnosed I $(N=184)^{e}$ & & Age when diagnosed $\|(N=184)^{e, g}$ & \\
\hline mean $(\mathrm{SD})^{\mathrm{b}}$ & $34.7(12.5)$ & $\geq 18$ years of age ${ }^{a}$ & 94.6 \\
\hline minimum ${ }^{c}$ & 3 & $\leq 18$ years of age ${ }^{a}$ & 5.4 \\
\hline maximum $^{c}$ & 60 & & \\
\hline
\end{tabular}

ain percent

${ }^{\mathrm{b}}$ means and standard deviation

cyears of age

${ }^{d}$ missing data $N=2$

emissing data $\mathrm{N}=1$

just the four most stated comorbidities are listed

${ }^{9}$ being $\geq 18$ years of age at first-time diagnosis is classified as late-diagnosed

Regarding the longest-practised and the current occupation, the highest proportion of participants was found in the occupational area "health and social sector, teaching and education" (22.4\% and $23.3 \%$, respectively) followed by "corporate organization, accounting, legal and administrative sectors" (19.3\% and 19.4\%, respectively). A comparison of participants' distribution across the various occupational areas (regarding their current occupation) with data from the German Federal Employment Agency [23] revealed a significant difference between the study sample and the general population $\left(\mathrm{Chi}^{2}=54.0\right.$; $\left.\mathrm{df} 8 ; p<.001\right)$. In particular, the proportion of participants working in the field of "natural sciences, geography and computer science" was higher than in the general population (c.f. Table 4).

Table 4 Occupational area by KldB

\begin{tabular}{|c|c|c|c|}
\hline Occupational area by KldB & $\begin{array}{l}\text { longest- practiced occupation } \\
(N=161)^{b}\end{array}$ & $\begin{array}{l}\text { current occupation } \\
(n=103)^{c}\end{array}$ & $\begin{array}{l}\text { occupation general } \\
\text { population }[23]^{\mathrm{d}}\end{array}$ \\
\hline Agricultural, forestry and horticulture sector ${ }^{a}$ & 1.2 & 1.0 & 1.5 \\
\hline Commodity extraction, production and manufacturing ${ }^{a}$ & 16.1 & 12.6 & 22.5 \\
\hline Construction, architecture, surveying ${ }^{a}$ & 2.5 & 3.9 & 5.8 \\
\hline Natural sciences, geography and informatics ${ }^{a}$ & 13.7 & 15.5 & 3.6 \\
\hline Traffic, logistics, protection and security ${ }^{a}$ & 9.3 & 9.7 & 13.2 \\
\hline Commercial services, commodity trading, sale, tourism ${ }^{a}$ & 9.3 & 8.7 & 12.1 \\
\hline Corporate organization, accounting, legal and administrative sectors ${ }^{a}$ & 19.3 & 19.4 & 20.6 \\
\hline Health and social sector, teaching and education ${ }^{a}$ & 22.4 & 23.3 & 17.7 \\
\hline $\begin{array}{l}\text { Linguistics, literature, humanities, social and economic sciences, } \\
\text { media, art, culture and design }{ }^{a}\end{array}$ & 6.2 & 5.8 & 2.7 \\
\hline
\end{tabular}

\footnotetext{
in percent

${ }^{b}$ missing data $N=6$; not classifiable $N=7$

Cmissing data $N=7$; not classifiable $N=9$

dno data available for the occupational area "armed forces"
} 


\section{Occupational skill level, inadequate employment and overeducation}

To assess inadequate employment in terms of over- or undereducation in participants who had ever been employed $(N=174)$ not including education and training $(N=9)$, a vocational orientation phase $(N=1)$, or a so-called one-euro-job ( $N=1$; one-euro jobs are public services jobs that pay at least one euro per hour and do not affect unemployment benefits in individuals who are registered as unemployed), the KldB skill levels with respect to the longest-practised occupation were compared with participants' highest level of formal education and training according to the KldB skill levels (missing data $N=9$ ). Likewise, for participants who were employed at the time of the survey $(N=119)$, not including education and training $(N=8)$, retraining $(N=1)$ or an internship $(N=1)$, the KldB skill levels with respect to the current occupation were also compared with participants' highest level of formal education and training according to the KldB skill levels (missing data $N=10$ ).

In Table 5, the column "all" shows the distribution of participants across $\mathrm{KldB}$ skill levels regarding their longest-practised and their current occupation. For both, the majority of participants were situated in skill level 2 (50.6\% and $41.4 \%$, respectively). The following columns in Table 5 sort participants into three categories relating to the match or mismatch between the skill level of their longest-practised respectively current occupation and their level of formal education and training according to the $\mathrm{KldB}$. In total, $62.3 \%$ were found to be at parity regarding the skill requirements of their longest-practised occupation, $15.6 \%$ were undereducated, meaning that their skill levels of formal qualification were below the occupational skill requirements, and $22.1 \%$ were classified as overeducated (c.f. Table 5). With respect to the current occupation $54.5 \%$ were found to be in parity, $14.1 \%$ were undereducated and $31.3 \%$ were classified as overeducated, meaning that their formal qualifications exceeded the skill requirements needed for the current occupation (c.f. Table 5).

According to data from the employment statistics of the German Federal Employment Agency, 63.0\% of the general population in Germany are at parity, $22.0 \%$ are undereducated and $15.0 \%$ are overeducated in their

Table 5 Occupational skill level, overeducation and undereducation

\begin{tabular}{|c|c|c|c|c|c|}
\hline \multicolumn{2}{|c|}{ skill level longest-practiced job ${ }^{a}$} & all & parity & undereducated & overeducated \\
\hline \multirow[t]{2}{*}{1} & $n$ & 16 & 4 & - & 12 \\
\hline & $\%$ & 10.4 & 25.0 & - & 75.0 \\
\hline \multirow[t]{2}{*}{2} & $\mathrm{n}$ & 78 & 56 & 7 & 15 \\
\hline & $\%$ & 50.6 & 71.8 & 9.0 & 19.2 \\
\hline \multirow[t]{2}{*}{3} & $n$ & 21 & 6 & 8 & 7 \\
\hline & $\%$ & 13.6 & 28.6 & 38.1 & 33.3 \\
\hline \multirow[t]{2}{*}{4} & $n$ & 39 & 30 & 9 & - \\
\hline & $\%$ & 25.3 & 76.9 & 23.1 & - \\
\hline \multirow[t]{2}{*}{ column total } & $\mathrm{n}$ & 154 & 96 & 24 & 34 \\
\hline & $\%$ & 100 & 62.3 & 15.6 & 22.1 \\
\hline \multicolumn{2}{|c|}{ skill level current job ${ }^{b}$} & all & parity & undereducated & overeducated \\
\hline \multirow[t]{2}{*}{1} & $n$ & 17 & 3 & - & 14 \\
\hline & $\%$ & 17.2 & 17.6 & - & 82.4 \\
\hline \multirow[t]{2}{*}{2} & $n$ & 41 & 26 & 2 & 13 \\
\hline & $\%$ & 41.4 & 63.4 & 4.9 & 31.7 \\
\hline \multirow[t]{2}{*}{3} & $n$ & 11 & 1 & 6 & 4 \\
\hline & $\%$ & 11.1 & 9.1 & 54.5 & 36.4 \\
\hline \multirow[t]{2}{*}{4} & $n$ & 30 & 24 & 6 & - \\
\hline & $\%$ & 30.3 & 80.0 & 20.0 & - \\
\hline \multirow[t]{2}{*}{ column total } & $n$ & 99 & 54 & 14 & 31 \\
\hline & $\%$ & 100 & 54.5 & 14.1 & 31.3 \\
\hline
\end{tabular}

${ }^{a} N=154$; missing data $N=9$; excluded because of being in education and training $N=9$, excluded because of stating the longest practiced occupation being a vocational orientation phase $N=1$ or a so-called one-euro-job $N=1$

${ }^{\mathrm{b}} N=99$; missing data $N=10$; excluded because of being in education and training $N=8$, excluded because of stating the present practiced occupation being retraining $N=1$ or an internship $N=1$ 
employment [25]. In this regard, there is a significant difference between the general population and the study sample with respect to under- and overeducation regarding the current occupation $\left(\mathrm{Chi}^{2}=21.0 ; \mathrm{df} 2 ; p<.001\right)$.

\section{Discussion}

This study aimed to examine the participation of clinically mostly late-diagnosed and most likely not intellectually disabled adults with ASD in the German labour market by means of a postal cross-sectional survey in former patients of the "specialised outpatient assessment clinic for ASD in adulthood" of the Medical Center University of Freiburg.

A sufficient response rate of $43.2 \%$ was achieved. However, as not all potential participants replied, the critical issue is the representativeness of this sample. It remains unclear whether individuals with, for instance, higher psychosocial functioning or better opportunities and achievements in the labour market were more likely to participate in this survey, which might have biased the results. It is most probable that the employment rate and appropriate occupational positions were overestimated, as it is well known in research that individuals are more likely to report positive aspects than negative aspects [29].

Although the majority of our sample was male, the proportion of women was higher than in the typical male-to-female ratio in ASD [30]. However, this ratio is in accordance with comparable studies, which showed higher proportions of women among late-diagnosed adults with ASD $[12,13,31]$. This might be explained by gender specific compensation strategies [32], for example imitation learning, which lead for example to a better social adjustment and therefore a later identification of ASD. Thus, the late first-time diagnosis in $94.6 \%$ of the participants in this sample can be deemed as a specificity of this study. Our sample probably represents a subsample of adults with ASD comprising more able individuals with comparatively good adaptive and compensatory social skills. This is also reflected in the specificity of our study design and sample, addressing adults with clinically mostly late-diagnosed ASD and most likely no co-occuring intellectual disability. As a consequence, this might also explain the high proportion of participants who were married or in a long-term relationship compared to other studies on psychosocial outcomes in adults with ASD [13, 33, 34]. However, high rates of self-reported comorbidities were found, comparable to those reported in other studies [13, 33], which might also influence participants' employment situation. All participants were at an employable age, with an age range of 21 to 64 years, and therefore represent the relevant target group of this survey.
Regarding the general level of education, the sample considerably exceeds the educational attainment of the general population, with $56.8 \%$ of participants possessing university entrance-level qualifications, compared to 29.5\% within the general population in Germany in 2015 [35]. In Germany the university graduate ratio was $32.0 \%$ in 2014 [36], and $14.8 \%$ of the general population possessed a Masters' or diploma degree as their highest vocational qualification in 2015 [35] and would therefore be assigned to skill level 4 of the KldB in terms of the level of formal education and training. This falls well below the percentage of study participants in our sample assigned to skill level 4 (24.9\%). As the proportion of participants with no qualifications $(10.5 \%)$ or a not further specified qualification $(2.8 \%)$ who can therefore be assigned to KldB skill level 1, is also below that of individuals with no vocational qualifications in the general population in Germany (16.8\%) in 2015 [35], our sample shows a comparatively high level of formal education and training in adults with late-diagnosed ASD, which potentially leads to promising chances in the labour market. In this respect - at first glance - participants' participation in the labour market seems satisfactory, as only $5.9 \%$ had never been employed. However, only $68.4 \%$ of those who had ever been employed were currently employed at the time of the survey. Moreover, a self-reported unemployment rate of $13.5 \%$ was found, which considerably exceeds the current unemployment rate in Germany, which lay at $6.4 \%$ in 2015 [37]. It appears that - despite partly high formal qualifications and a share of $49.0 \%$ of participants having never experienced times of unemployment - adults with ASD often experience problems in maintaining stable employment relationships. In this regard, international studies suggest, that challenges in maintaining employment in adults with ASD can be explained by social and sensory issues interfering with their job performance as well as their ability to manage interactional aspects of work [46]. In view of the fact that $17.0 \%$ of those participants who had ever been employed later retired early for health reasons, and taking into account the reported high prevalence of comorbidities, it would appear that employment support is necessary that takes into account the specific characteristics of ASD regarding social and sensory issues, as well as further health-related aspects regarding the ability to work.

Although we found a strong trend towards occupations within the area "natural sciences, geography and computer sciences" compared to the general population [23], adults with ASD cover a broad range of occupational areas. In particular, the occupational area "health and social sector, teaching and education" was represented by a high proportion of our sample. This result does not tie in with the stereotype that adults with ASD 
are only found in more technically orientated, and not socially orientated, professions. These findings are in line with a study by Baldwin et al. [15] who also found that adults with ASD are employed in a wide variety of different occupational environments.

Even though the proportion of participants who were inadequately employed and overeducated was lower than that found in similar studies [12, 15], a significant difference emerged compared to the general population regarding the current occupation, with $31.3 \%$ of participants being inadequately employed in terms of overeducation. Moreover, the proportion of participants who were overeducated in their current profession was higher than the proportion of participants who were overeducated in their longest practised profession (22.1\%). Thus, it appears that adults with ASD are partly unable to maintain professional positions in accordance with their level of formal qualification. This finding can be linked to studies, showing that differences with employers, i.e. regarding the understanding of productivity requirements and selforganization of work tasks, or possible ASD-related issues, i.e. impaired ability to handle social aspects, can hinder successful participation in the labour market [5-10].

According to our findings, while adults with ASD as seen in our specialised outpatient clinic have above-average levels of formal education and training, at least in part, they experience problems and challenges to establish themselves in the German labour market and/or to sustain professional positions that are appropriate to their level of formal education and training. This is alarming and in need of explanation. It can be assumed that the constraints associated with ASD are better compensated in educational contexts, as potentially impaired executive and soft-skills meet with higher tolerance, and individuals with ASD experience more assistance than is provided in working environments. Furthermore, greater flexibility and autonomy for individuals to utilize their own style of learning and working, with reduced impact of social difficulties, may also be a factor in the higher attainment of individuals with ASD in educational context compared with their employment status. This underlines the need for a better integration and improved support of adults with ASD in occupational settings, and demonstrates that potential strengths associated with ASD, such as honesty, efficiency or precision [38], should be identified and reinforced. This is of particular relevance since support programs for adults with ASD, addressing, e.g., work preparation and communication with employers, proved to be effective in increasing employment rates $[39,40]$. A promising approach to meet the support requirements of adults with ASD could be "training-onthe-job" measures, as the most important issue does not seem to lie in obtaining professional positions, but rather in maintaining them. For the development and implementation of such measures, further research on the experience of employment situations in adults with ASD is needed, i.e. expectations regarding workplace design, challenges in professional transitions or experiences with ASD related sensory and interactional difficulties in occupational environments as well as support needs concerning these matters.

\section{Conclusions}

Despite an above-average level of general education in terms of school-leaving qualifications and a high level of formal education and training, even exceeding the level within the general population, adults with late-life diagnosis of ASD are at a disadvantage regarding their participation in the labour market in Germany. Consequently, there are high rates of unemployment and early retirement for health reasons represented in our sample. Furthermore, adults with ASD seem to struggle to maintain professional positions that are appropriate to their formal qualifications and are often inadequately employed in terms of overeducation. Based on the results of our study, and on previous studies demonstrating good outcomes from employment support programs, the development of "training-on-the-job" interventions seems particularly promising to enhance the labour market participation of adults with ASD.

\section{Additional file}

Additional file 1: Questionnaire. (PDF $145 \mathrm{~kb}$ )

\section{Abbreviations}

ASD: Autism spectrum disorder; DSM-IV: Diagnostic and Statistical Manual of Mental Disorders 4th Revision; ICD-10: International Statistical Classification of Diseases and Related Health Problems 10th Revision; IQ: Intelligence quotient; KIdB: Classification of occupation 2010; NICE: National Institute for Health and Care Excellence

\section{Acknowledgements}

The article processing charge was funded by the German Research Foundation (DFG) and the Albert-Ludwigs-University Freiburg in the funding programme Open Access Publishing. We thank Sarah Mannion for copyediting the manuscript

\section{Funding}

Not applicable.

\section{Availability of data and materials}

The datasets generated and analysed during the current study are not publicly available due to this being one part of an ongoing project at the Research Group on Psychotherapy and Health Services Research of the Department of Psychiatry and Psychotherapy of the Medical Center University of Freiburg, Faculty of Medicine, University of Freiburg. The datasets are planned to be used in further analyses and publications, but are available from the corresponding author on reasonable request.

\section{Authors' contributions}

FF coordinated the study, participated in formulating the research question, participated in designing the study and the questionnaire, performed the statistical analyses and wrote the paper. MJ participated in the coordination of the study, participated in designing the study and the questionnaire, performed the data acquisition and data management and supported the 
statistical analyses. TA substantially supported data management as well as the statistical analyses and edited various drafts of the paper. AR and TF participated in formulating the research question, contributed substantially to designing the study and the questionnaires and supported data acquisition. LPH and LTVE formulated the research question, conceptualized the study design and supervised the study. All authors revised the manuscript critically for important intellectual content and read and approved the final manuscript.

\section{Ethics approval and consent to participate}

The Ethics Review Committee of the Medical Centre - University of Freiburg approved the study protocol as well as study procedures and materials (288/15). All potential participants received information on the study and a questionnaire by post. The study was conducted with full anonymity and voluntary participation. Consent to participate was granted by returning the questionnaire. This approach was explained in detail within the study information. Based on the results of the diagnostic approach presented above, an overseeing medical adviser (LTVE) had concluded that all participants were capable of providing ethical consent for their participation.

\section{Consent for publication}

Not applicable.

\section{Competing interests}

The authors declare that they have no competing interests.

\section{Publisher's Note}

Springer Nature remains neutral with regard to jurisdictional claims in published maps and institutional affiliations.

\section{Author details}

'Department of Psychiatry and Psychotherapy, Medical Center - University of Freiburg, Faculty of Medicine, University of Freiburg, Hauptstraße 5, 79104 Freiburg, Germany. ${ }^{2}$ Department of Social Work, Protestant University of Applied Sciences Freiburg, Bugginger Straße 38, 79114 Freiburg, Germany. ${ }^{3}$ Department of Oncological Rehabilitation - UKF Reha gGmbH, Medical Center - University of Freiburg, Breisacher Straße 117, 79106 Freiburg, Germany. ${ }^{4}$ Parkklinik Wiesbaden Schlangenbad, Rheingauer Straße 47, 65388 Schlangenbad, Germany.

\section{Received: 26 May 2017 Accepted: 2 March 2018}

Published online: 27 March 2018

\section{References}

1. Wing L. The autistic spectrum: a guide for parents and professionals. 2nd ed. London: Robinson; 2003.

2. American Psychiatric Association. Diagnostic and statistical manual of mental disorders: DSM-5. Washington, D.C: American Psychiatric Association; 2013.

3. Fried R, Joshi G, Kotte A, Kagan E, Biederman J. Toward developing a simulated workplace laboratory for adults with high functioning autism spectrum disorders. Open J Psychiatr. 2013; https://doi.org/10.4236/ojpsych. 2013.33032.

4. Kirchner JC, Dziobek I. Towards successful employment of adults with autism: a first analysis of special interests and factors deemed important for vocational performance. Scand J Child Adolesc Psychiatry Psychol. 2014;2:77-85.

5. Vogeley K, Kirchner JC, Gawronski A, Tebartz van Elst L, Dziobek I. Toward the development of a supported employment program for individuals with high-functioning autism in Germany. Eur Arch Psychiatry Clin Neurosci. 2013;263:197-203.

6. Lawer L, Brusilovskiy E, Salzer MS, Mandell DS. Use of vocational rehabilitative services among adults with autism. J Autism Dev Disord. 2009; 39:487-94.

7. Barnhill GP. Outcomes in adults with Asperger syndrome. Focus Autism Dev Disabil. 2007:22:116-26.

8. Howlin P. Social disadvantage and exclusion: adults with autism lag far behind in employment prospects. J Am Acad Child Adolesc Psychiatry. 2013;52(9):897

9. Barnard J, Harvey V, Potter D, Prior A. Ignored or ineligible?: the reality for adults with autism spectrum disorders. London: National Autistic Society; 2001.
10. Scott M, Falkmer M, Girdler S, Falkmer T. Viewpoints on factors for successful employment for adults with autism spectrum disorder. PLoS One. 2015; https://doi.org/10.1371/journal.pone.0139281.

11. Theunissen G, Kulig W, Leuchte V, Paetz H. Handlexikon Autismus-Spektrum: Schlüsselbegriffe aus Forschung, Theorie, Praxis und Betroffenen-Sicht. Stuttgart: Kohlhammer Verlag; 2014

12. Riedel A, Schröck C, Ebert D, Fangmeier T, Bubl E, Tebartz van Elst L. Überdurchschnittlich ausgebildete Arbeitslose - Bildung, Beschäftigungsverhältnisse und Komorbiditäten bei Erwachsenen mit hochfunktionalem Autismus in Deutschland. Psychiatr Prax. 2016;43:38-44

13. Hofvander B, Delorme R, Chaste P, Nydén A, Wentz E, Ståhlberg O, et al. Psychiatric and psychosocial problems in adults with normal-intelligence autism spectrum disorders. BMC Psychiatry. 2009;9:35.

14. Barneveld PS, Swaab H, Fagel S, van Engeland H, de Sonneville LMJ. Quality of life: a case-controlled long-term follow-up study, comparing young highfunctioning adults with autism spectrum disorders with adults with other psychiatric disorders diagnosed in childhood. Compr Psychiatry. 2014;55: 302-10.

15. Baldwin S, Costley D, Warren A. Employment activities and experiences of adults with high-functioning autism and Asperger's disorder. J Autism Dev Disord. 2014:44:2440-9.

16. Hendricks D. Employment and Adults with autism spectrum disorders: challenges and strategies for success. J Vocat Rehabil. 2010;32:125-34.

17. National Institute for Health and care Excellence. Autism: guidance and guidelines. 2014. https://www.nice.org.uk/guidance/qs51 22137029. Accessed 9 Mar 2018.

18. DGKJP, DGPPN. S3-Leitlinie Autismus-Spektrum-Störungen im Kindes-, Jugend- und Erwachsenenalter: Teil 1: Diagnostik. 2016. http://www.awmf org/leitlinien/detail/II/028-018.html. Accessed 9 Mar 2018.

19. Tebartz van Elst L, Maier S, Fangmeier T, Endres D, Mueller GT, Nickel $K$, et al. Disturbed cingulate glutamate metabolism in adults with high-functioning autism spectrum disorder: evidence in support of the excitatory/inhibitory imbalance hypothesis. Mol Psychiatry. 2014:19:1314-25.

20. Edwards P, Roberts I, Clarke M, DiGuiseppi C, Pratap S, Wentz R, et al. Methods to increase response rates to postal questionnaires. Cochrane Database Syst Rev. 2007; https://doi.org/10.1002/14651858.MR000008.pub4.

21. Bundesagentur für Arbeit. Klassifikation der Berufe 2010. Nürnberg: Bundesagentur für Arbeit; 2011.

22. Bundesagentur für Arbeit: Dokumentationskennziffern. https://berufenet. arbeitsagentur.de/berufenet/faces/index;BERUFENETJSESSIONID= igMKTSoAdFmegFtRNTwCb3Kwlhc4-oXDsRKI0XOYeiEdtbfttsCa!1293359102?path=null; 2015. Accessed 9 Mar 2018.

23. Bundesagentur für Arbeit. Berichterstattung nach Berufen: ausgeübte berufliche Tätigkeit. 2016. https:/statistik.arbeitsagentur.de/Statistikdaten/ Detail/201603/iiia6/beschaeftigung-berufe-sektoren/berufe-sektoren-12-0201603-xIsx.xIsx. Accessed: 30 Mar 2017.

24. Paulus W, Matthes B. FDZ-Methodenreport 08/2013 Klassifikation der Berufe 2010: Struktur, Codierung und Umsteigeschlüssel. Nürnberg: Bundesagentur für. Arbeit. 2013;

25. Reichelt M, Vicari B. IAB-Kurzbericht 25/2014 Ausbildungsinadäquate Beschäftigung in Deutschland. Nürnberg: Institut für Arbeitsmarkt- und Berufsforschung; 2014

26. Scheidt-Nave C, Kamtsiuris P, Gößwald A, Hölling H, Lange M, Busch MA, et al. German health interview and examination survey for adults (DEGS) design, objectives and implementation of the first data collection wave. BMC Public Health. 2012;12:730

27. Riedel A, Suh H, Haser V, Hermann I, Ebert D, Riemann D, et al. Freiburg questionnaire of linguistic pragmatics (FQLP): psychometric properties based on a psychiatric sample. BMC Psychiatry. 2014;14:374.

28. Someren MW, Barnard YF, Sandberg JAC. The think aloud method: a practical guide to modelling cognitive processes. London: Academic Press; 1994.

29. Fadnes LT, Taube A, Tylleskär T. How to identify information bias due to self-reporting in epidemiological research. IJE. 2009;7(2)

30. Fombonne E, Quirke S, Hagen A. Prevalence and Interpretation of recent trends in rates of pervasive developmental disorders. Mcgill $J$ Med. 2009;12:73.

31. Lehnhardt FG, Gawronski A, Volpert K, Schilbach L, Tepest R, Vogeley K. Das psychosoziale Funktionsniveau spätdiagnostizierter Patienten mit AutismusSpektrum-Störungen - eine retrospektive Untersuchung im Erwachsenenalter. Fortschritte Neurol Psychiatr. 2012;80:88-97. 
32. Dworzynski K, Ronald A, Bolton P, Happé F. How different are girls and boys above and below the diagnostic threshold for autism spectrum disorders? J Am Acad Child Adolesc Psychiatry. 2012;51:788-97.

33. Howlin P. Outcome in adult life for more able individuals with autism or Asperger syndrome. Autism. 2000;4:63-83.

34. Engström I, Ekström L, Emilsson B. Psychosocial functioning in a group of Swedish adults with Asperger syndrome or high-functioning autism. Autism. 2003;7:99-110.

35. Statistisches Bundesamt. Bildungsstand: Bevölkerung nach Bildungsabschluss in Deutschland. 2015. https://www.destatis.de/DE/ ZahlenFakten/GesellschaftStaat/BildungForschungKultur/Bildungsstand/ Tabellen/Bildungsabschluss.html. Accessed 6 Apr 2017.

36. Autorengruppe Bildungsberichterstattung. Bildung in Deutschland 2016: Ein indikatorengestützter Bericht mit einer Analyse zu Bildung und Migration. Bielefeld: W. Bertelsmann Verlag; 2016.

37. Bundesagentur für Arbeit. Arbeitslosenquote in Deutschland im Jahresdurchschnitt von 1995 bis 2017. 2017. https://de.statista.com/statistik/ daten/studie/1224/umfrage/arbeitslosenquote-in-deutschland-seit-1995/. Accessed 6 Apr 2017.

38. Müller E, Schuler A, Burton BA, Yates GB. Meeting the vocational support needs of individuals with Asperger syndrome and other autism spectrum disabilities. J Vocat Rehabil. 2003;18:163-75.

39. Mawhood L, Howlin P. The outcome of a supported employment scheme for high-functioning adults with autism or Asperger syndrome. Autism. 1999;3:229-54.

40. Wehman PH, Schall CM, McDonough J, Kregel J, Brooke V, Molinelli A, et al. Competitive employment for youth with autism spectrum disorders: early results from a randomized clinical trial. J Autism Dev Disord. 2014;44:487-500.

\section{Submit your next manuscript to BioMed Central and we will help you at every step:}

- We accept pre-submission inquiries

- Our selector tool helps you to find the most relevant journal

- We provide round the clock customer support

- Convenient online submission

- Thorough peer review

- Inclusion in PubMed and all major indexing services

- Maximum visibility for your research

Submit your manuscript at www.biomedcentral.com/submit 